\title{
Clinical and Radiographic Features of Ameloblastoma: Ultimate Diagnosis and Treatment
}

\author{
Adnan Ali Shah ${ }^{1} \quad$ Muhammad Amjad Bari ${ }^{2} \quad$ Saima Munir $^{2} \quad$ Noorul Ain Arshad ${ }^{2} \quad$ Khalil Ahmad Khan $^{2}$ \\ Sohail Fareed ${ }^{2}$ \\ 1.Professor of Oral and Maxillofacial Surgery. Department Head, Dental Diagnostic and Surgical Sciences, \\ Division Head and Graduate Program Director OMFS. Head OMFS Health Sciences Center. D344A - 790 \\ Bannatyne Ave, College of Dentistry, Faculty of Health Sciences,University of Manitoba. \\ 2.Nishtar Institute Dentistry, Multan
}

\begin{abstract}
Objectives: The purpose of this study was to compare the clinical and radiographic features of 22 intraosseous ameloblastomas. Study design: All the data with respect to the patient's age, sex, tumor locations, surgical treatment history, as well as radiographic findings and number of recurrence, were analyzed. Results: The patient's age at biopsy ranged from 08 to 70 years (mean, 31.5 years), Fourteen $(63.6 \%)$ of the 22 subjects were females, and eight $(36.4 \%)$ were males. Nineteen $(86.4 \%)$ of the 22 ameloblastomas were located in mandible and three $(13.6 \%)$ were located in maxilla. Pain, swelling and purulent discharge were the most common symptoms and were experienced by eight (36.4\%) patients. Radiographically, seventeen $(77.3 \%)$ of the 22 tumors were multilocular. Remaining five cases were unilocular with a well-demarcated border. There was no case exhibiting the typical soap-bubble appearance. The most common histologic pattern was plexiform and had follicular type. Conclusion: Diagnosis of ameloblastoma remained in doubt after clinical and radiographic examination. A biopsy is necessary for the confirmation of diagnosis. Surgical treatment should be planned after C.T and 3D Scan. Longterm follow-up at regular intervals after surgery is also recommended.
\end{abstract}

Keywords: Ameloblastoma, Diagnosis, Radiographic

DOI: $10.7176 / \mathrm{JMPB} / 60-02$

Publication date:October $31^{\text {st }} 2019$

\section{Introduction}

Ameloblastomas are an enigmatic group of oral tumors. The general agreement that ameloblastomas are odontogenic in origin occurs largely on the basis of the histological similarities of the tumor and the developing enamel organ. (1-5) Ameloblastomas in young people (i.e., those 19 years old and younger) are thought to be rare. They account for approximately $10 \%$ to $15 \%$ of all reported cases of ameloblastoma.(6,7) Several causative factors have been proposed, including (1) nonspecific irritating factors such as extraction, caries, trauma, infection, inflammation, or tooth eruption; (2) nutritional deficit disorders; and (3) viral pathogenisis. (8). The pathology of ameloblastoma is generally well understood and includes the importance of separating this tumor into three types, each with its own distinctive clinical behavior and response to treatment. Two factors are of major important concerning the biologic behavior and therefore the treatment of classic intraosseous ameloblastoma. The first is that it infiltrates cancellous bone but is largely confined by compact bone; the second is the location of the tumor within the jaw. Ameloblastoma has a well-deserved reputation for recurrence after curettage. Gold's well-reasoned argument that the ameloblastoma should be considered a low-grade malignant tumor should be noted. (9) This infiltration of cancellous bone has two important consequences clinically. First, the tumor extends beyond its radiologically apparent margin. Second, recurrence is to be expected if the clinician accepts the radiologic margin of the tumor in cancellous bone as its actual limit and creates the lesion on that basis. Consequently, attempts have been made to remove any tumor that has extended beyond its radiologic margins by the use of various forms of cautery or by removing bone from the surgical cavity with a bur (peripheral ostectomy). The location of ameloblastoma in the jaw is important. First, the farther the tumor is from vital structures, the less likely it is to infiltrate them. It follows that ameloblastomas of the body of mandible and of the anterior maxilla are less dangerous than those of the ascending ramus and especially those of the posterior maxilla. Secondly, the entire maxilla, unlike the mandible, possesses a very thin cortical plate; moreover, the layers of bone between the apices of the posterior teeth and the floor of the maxillary sinus are often extremely thin. Consequently, the maxilla does not possess the effective barrier to the spread of ameloblastoma that a thick cortical plate provides, and the ameloblastoma can therefore readily spread into adjacent structures. Complete excision, including removal of an extensive margin of apparently unaffected bone, is also the standard treatment for mandibular ameloblastomas. Unicystic ameloblastomas generally resemble dentigerous cysts clinically and radiologically. They typically occur more often in younger persons, mainly in the second and third decades of life, than do classic intraosseous ameloblastomas. (10-11)

The diagnosis of unicystic ameloblastoma is based on two features. First, the lesion must be unilocular, clinically and radiologically. Second, on microscopic examination it must appear as a single cystic lesion with the 
epithelial lining consisting of ameloblastoma. The importance of the unicystic ameloblastoma is that it possesses a much better prognosis after enucleation or curettage than does the classic intraosseous ameloblastoma. (10-14) The reason for this better prognosis is that in many examples the ameloblastoma involves only the epithelial lining of the cyst or project into its lumen. Its recurrence rate after these procedures is around 15\%, whereas recurrence is much higher after curettage of classic intraosseous ameloblastoma. These lesions, which are sometimes referred to as luminal or intraluminal ameloblastomas, respectively, are confined by the fibrous connective tissue wall of the cyst and are consequently removed completely if the cyst is enucleated. Theoretically, they do not recur.

However, other unicystic ameloblastomas may recur. They are the so called mural ameloblastomas that have involved the connective tissue wall of the cyst from their origin in the epithelial lining of the cyst, or possibly they have arisen from rests of odontogenic epithelium within the wall of the cyst and that have subsequently invaded the surrounding bone. At this stage, a unicystic ameloblastoma will act as a classic intraosseous ameloblastoma and has to be treated as such. A unicystic ameloblastoma only enjoys a good prognosis if it is still confined within the fibrous connective tissue wall of the cyst.

The peripheral ameloblastoma is defined as an ameloblastoma that is confined to the gingival or alveolar mucosa. It infiltrates the surrounding tissues, basically the gingival connective tissue, like any other ameloblastoma but it does not invade the underlying bone. The peripheral ameloblastoma is readily cured by complete excision including a microscopically proven tumor-free zone of tissue surrounding the tumor's lateral and deep margins. There are two major reasons why the peripheral ameloblastoma has a good prognosis. First it appears as a gingival growth and as such it is readily noticeable; it is therefore normally excised early in its development. The second reason is that the cortical bone of the jaws, which represents such a barrier to the classic intraosseous ameloblastoma's breaking out of bone, is just as efficient a barrier to the invasion of the jaw by a peripheral ameloblastoma. In addition, the dense fibrous connective tissue of the gingiva probably provides more resistance to the spread of tumor than does the delicate connective tissue of the intertrabecular spaces of cancellous bone. Desmoplastic ameloblastoma is a new development. The islands of ameloblastoma are surrounded and often compressed by a dense and sometimes hyalinized fibrous connective tissue. The desmoplastic ameloblastoma involves the anterior maxilla predominantly, which is an unusual location for ameloblastoma although it also involves the anterior mandible quite commonly, and presents a radiographic appearance that is more typical of a benign fibroosseous lesion than of ameloblastoma.

Almost all ameloblastomas are cytologically benign, but very occasionally a lesion that is otherwise microscopically a typical ameloblastoma exhibits cytologic evidence of a malignant condition. Such tumors are referred to as ameloblastic carcinomas as opposed to malignant ameloblastomas; the latter are cytologically benign tumors that unexpectedly metastasize and are so rare as to be considered curiosities.

\section{SUBJECTS AND METHODS}

Twenty-two patients with ameloblastoma were treated at our hospital between January 2003 and September 2004. All clinical and radiological information with respect to age, sex, symptoms, and location were verified. The patients were treated conservatively (i.e., with enucleation, curettage and peripheral ostectomy) or radically (i.e., with partial jaw resection). Histology slides from each case were reviewed and classified according to histological patterns.

\section{RESULTS}

The study group consisted of 8 males and 14 females with a mean age of 31.6 years (8-70 years; Table I and II). In 19 cases $(86.4 \%)$, the tumor was located in the mandible, and in 3 cases $(13.6 \%)$, the tumor was located in maxilla. Of the 19 mandibular lesions, $13(59.1 \%)$ were located in the mandibular body and ramus (Table III). Pain, swelling and purulent discharge were the most common symptoms, experienced by $8(36.4 \%)$ of the 22 patients (Table IV). Second most common symptom was pain and swelling experienced by 7 (31.8\%), and swelling was observed only in $6(27.3 \%)$ out of the 22 patients. Radiographically, $5(22.7 \%)$ of the 22 cases were unilocular with a well-demarcated border, whereas $17(77.3 \%)$ were multilocular in appearance (Table V). There was no case that exhibited a soap-bubble appearance. 
Graph-1: Percentage of patients according to gender

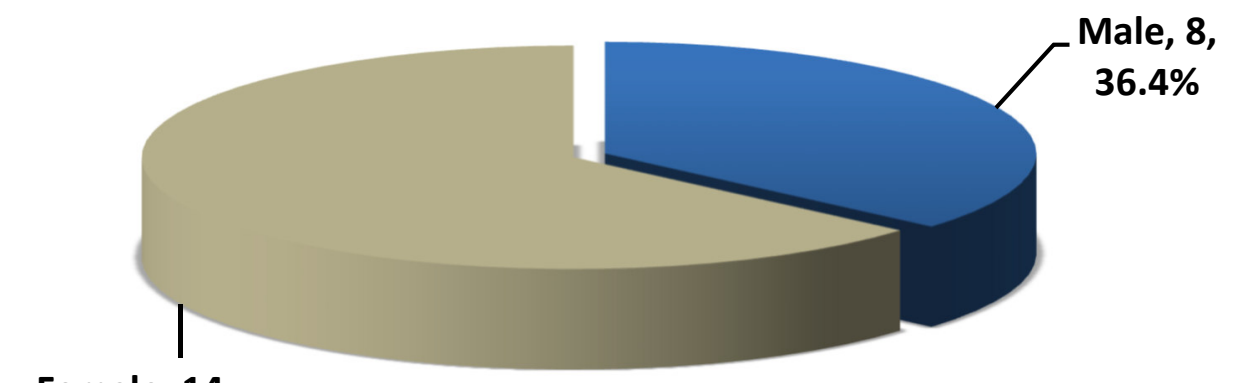

Female, 14,

$63.6 \%$

Graph-2: Frequency distribution of age groups

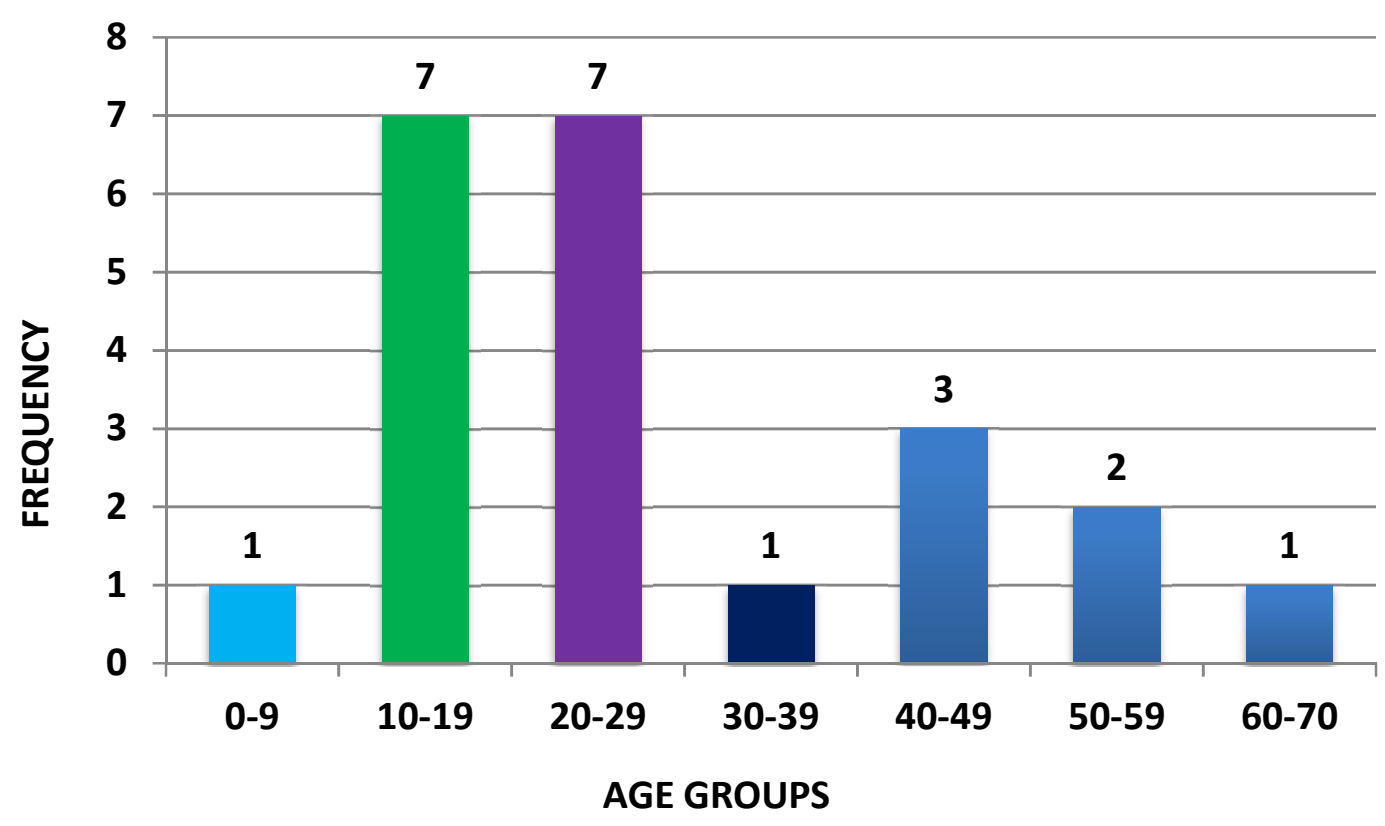

Graph-3: Percentage of complaints

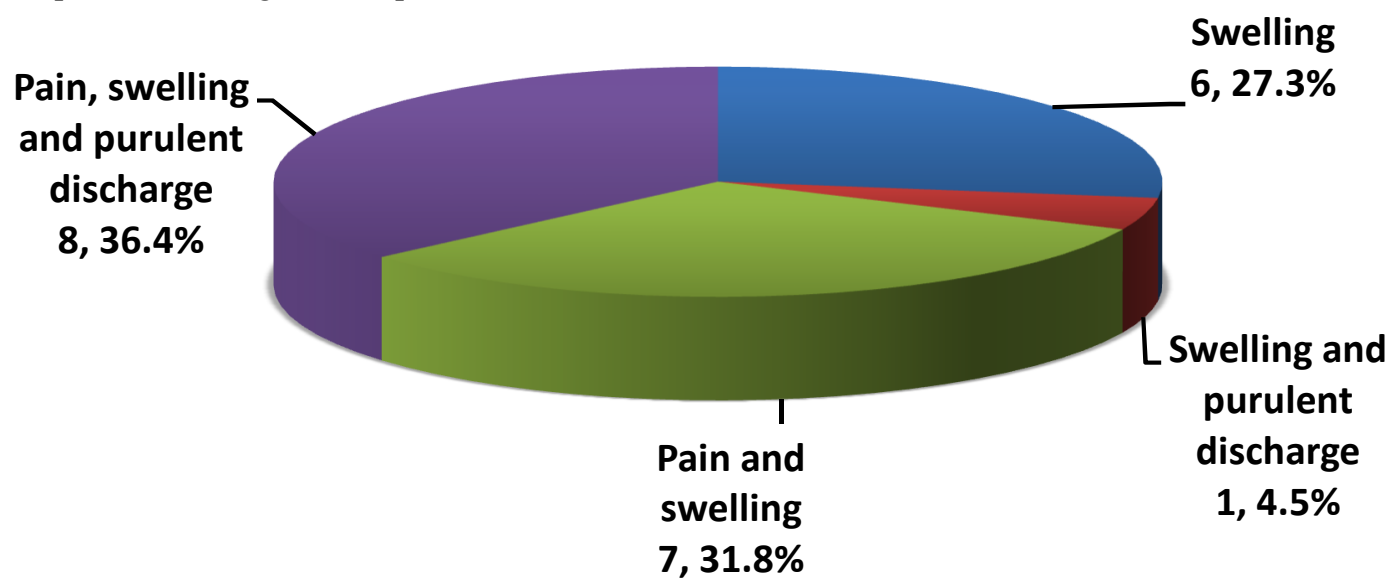


Graph-4: Frequency distribution of sites of ameloblastoma

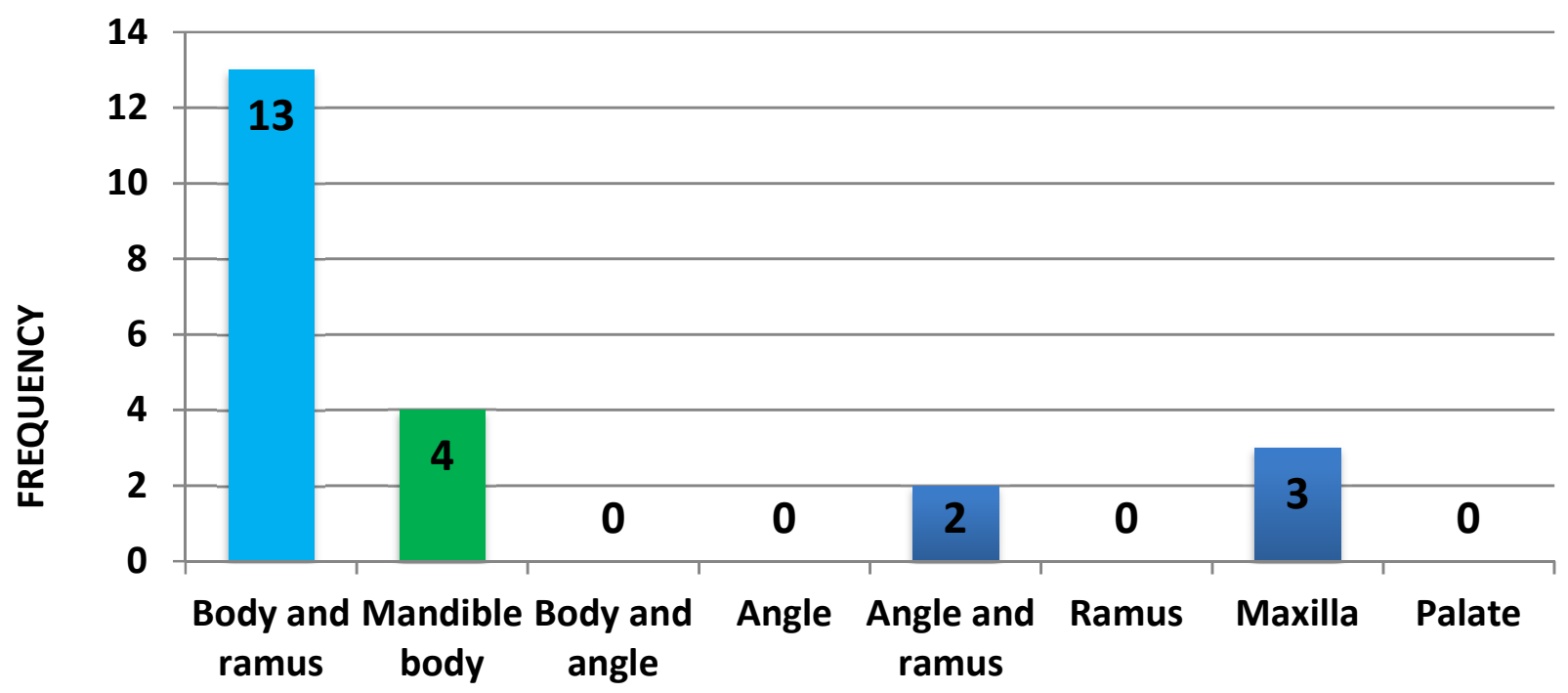

Sites of ameloblastoma

\section{DISCUSSION}

It has been reported previously that unilocular ameloblastomas tend to occur in younger age groups. Our results confirmed this tendency. In unilocular ameloblastoma, $4(80 \%)$ out of 5 cases occurred in teenage group. It was also reported that ameloblastoma in young people (i.e., those of 19 years old and younger) are $10 \%$ to $15 \%$ of all reported cases of ameloblastoma. $(6,7)$ Our study has not confirmed this tendency. There were $8(36.4 \%)$ cases of ameloblastomas which occurred in teenage group. The average age of patients with intraosseous ameloblastoma has been reported to be 39 years. In this study, we documented the occurrence of ameloblastomas in a significantly younger age group i.e., $16(72.7 \%)$ cases of ameloblastomas out of total 22 cases. The mean age of our patients at biopsy was 30.6 years (Table I). This variation may reflect ethnic differences or diagnosis within a health care system. Waldron and El-Mofty(15) reported that in 116 tumors, the male-to-female ratio was $1.2: 1$, which is in contrast to our results. In our study male-to-female ratio is $1: 1.8$, which is quite variation to the literature (Table I). Our studies show that ameloblastomas have a marked predilection for the mandible (86.4\%).

Pain, swelling and purulent discharge accounts for $36.4 \%$ of the symptoms and was the most common complaint of the patients in this study. Ameloblastomas are treated by curettage only, enucleation, peripheral ostectomy and radical surgery. $(14,16)$ Ameloblastoma of the maxilla should be treated as radically as possible. However, ameloblastoma that appears as unilocular lesions radiographically may be treated conservatively (i.e., with enucleation or curettage, or both) whereas all areas of the cystic lumen can be controlled intraoperatively. Supraperiosteal resection of the bone is necessary when extensive thinning or perforation of the cortical plates is noted. Chemotherapy and radiation seem to be contraindicated. (14). Postoperative follow-up is important in the management of ameloblastoma because more than $50 \%$ of all recurrence occurs within 5 years of surgery. In contrast to other reports, we found that most ameloblastomas occurred in the $3^{\text {rd }}$ decade of life. Long-term followup at regular intervals after surgery is also recommended.

\section{Conclusion:}

Diagnosis of ameloblastoma remained in doubt after clinical and radiographic examination. A biopsy is necessary for the confirmation of diagnosis. Surgical treatment should be planned after C.T and 3D Scan. Long-term followup at regular intervals after surgery is also recommended.

\section{REFERENCES}

1. Shafer WG, Hine MK, Levy BM. A textbook of oral pathology. 5th ed. Philadelphia: WB Saunders; 1983. p. 276-85.

2. Regezi JA Sciubba JJ. Oral pathology: clinical-pathologic correlations, Philadelphia: WB Saunders; 1989. p. 363-74.

3. Cawson RA, Binnie WH, Speight PM, Barrett AW Wright JM. Lucas's pathology of tumors of the Oral tissues. 5th ed. Hong Kong: Churchill Livingstone; 1988:25-32.

4. Eveson JW, Scully C. Color atlas of oral pathology. 1st ed. Barcelona: Mosby-Wolf; 1995. p. 43-5. 
5. Neville BW, Damm DD, Allen CM, Bouquot JE. Oral and Maxillofacial Pathology: WB Saunders; 1995. p. 512-520.

6. Keszler A, Dominguez FV. Ameloblastoma in childhood. J Oral Maxillofacial Surg 1986;44:609-13

7. Ueno S, Nakamura S, Mushimoto K, Shirasu R. A clinicopathologic study of ameloblastoma. J Oral Maxillofacial Surg 1986;44:361-5.

8. Csiba A, Okros I, Dzsinich CS, Szabo D. Virus-like particles in a human ameloblastoma. Arch Oral Biol 1970;15:817-26.

9. Gold L. Biologic behavior of ameloblastoma. Oral Maxillofac Surg Clin. North Am 1991;1:21-71.

10. Robinson L, Martinez MG. Unicystic ameloblastoma: a prognostically distinct entity, Cancer 1977; 40:227885.

11. Gardner DG, Corio RL. Plexiform ameloblastoma: a variant of ameloblastoma with a low recurrence rate after enucleation. Cancer 1984;53:1730-5.

12. Leider AS, Eversole LR, Barkin ME. Cystic ameloblastoma: a clinicopathological analysis. Oral Surg Oral Med Oral Pathol 1985;60:624-30.

13. Ackerman GL, Altini M, Shear M. The unicystic ameloblastoma : a clinicopathological study of 57 cases. J Oral Pathol Med 1988;17:541-6.

14. Reichart PA, Philipsen HP, Sonner S. Ameloblastoma: biologic profile of 3677 cases. Oral Oncol, Eur J Cancer 1995;31B:86-99.

15. Waldron CA, EL-Mofty SK. A histopathologic study of 116 ameloblastomas with special reference to the desmoplastic variant. Oral Surg Oral Med Oral Pathol 1987;63:441-51.

16. IsacssonG,Andersson L, Forsslund h, Bodin I, ThomssonM. Diagnosis and treatment of the unicystic ameloblastoma. Int J Oral Maxillofac Surg 1986;15:759-64. 